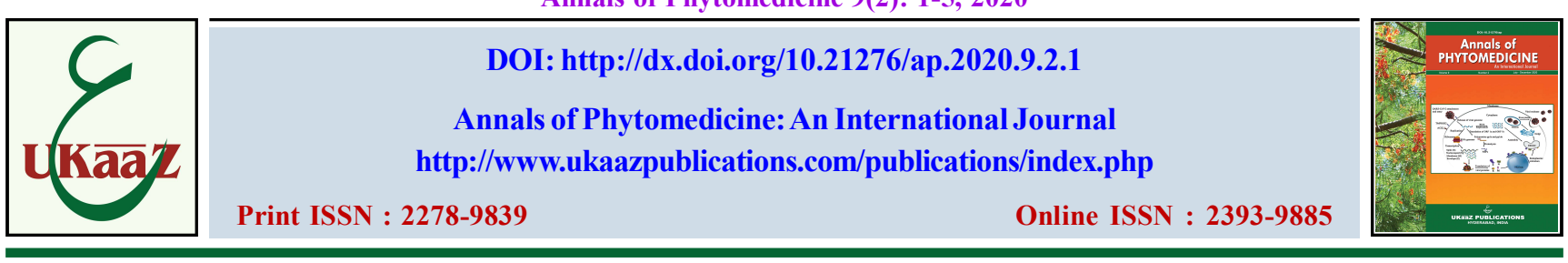

Invited commentary: Open access

\title{
Role of Unani medicine in empowering national healthcare
}

\author{
Asim Ali Khan \\ Central Council for Research in Unani Medicine (CCRUM), Ministry of AYUSH, Govt. of India, New Delhi-110058, India
}

Article Info

Article history: Received 1 November 2020 | Revised 18 December 2020 | Accepted 20 December 2020 | Published online 30 December 2020

The Unani healthcare system is one of the recognized medicinal practice of India that is holistic in nature and is based on the adaptation of the human body to the environment. It was developed and given the status of science in Greece, roots of which can be traced back to its earlier originators in ancient Egypt and its sister civilization Mesopotamia. Its earlier pharmaceutical texts reflect familiarity with fairly elaborate chemical operations for the purification of crude plant, animal, and mineral components. Plants and herbs were so important to ancient medicine that the terms for 'medicine' and 'herbs' were essentially equivalent (Magner, 2005). It is believed to have been established by the great physician and philosopher, Hippocrates (460-377 BC). It was later developed by Arabs, nurtured by Persians and further established as modern day science in Indian subcontinent (Rahman et al., 2008; Sudhir, 2014). The theoretical framework of Unani medicine is based on the teachings of Hippocrates, the father of medicine. The three fundamentals of Hippocratic Medicine were observation, experience, and rational principles, which still hold valid in the field of Medicine and Science (Kleisiaris et al., 2014).

Unani and Ayurveda have certain similarities. Both Ayurveda and Unani medicines are based on the concept that the human body constitutes of basic elements, i.e., air, water, fire and earth. In addition, Ayurveda considers akash also as one the basic element. An imbalance in these elements causes diseases. Both systems advocate various processes for cleansing and purification of the body and prescribe medicines made from natural substances (Ravishankar and Shukla, 2007). Unani medicine recognizes the influence of surroundings and ecological conditions on the state of health of human beings. Apart from treating disease conditions, Unani medicine lays great emphasis on the prevention of disease and promotion of health (Kleisiaris et al., 2014). The formulations and composition for Unani medicines are different from Ayurveda. In a completely healthy person, Unani prescribes lifestyle, diet and environment appropriate for his or her temperament, while for those who have become vulnerable to disease, special diets,

Corresponding author: Professor Asim Ali Khan

Director General, Central Council for Research in Unani Medicine (CCRUM), Ministry of AYUSH, Govt. of India, New Delhi-110058, India

E-mail: asim.ccrum@gmail.com

Tel.: +91-9811794448

Copyright $(92020$ Ukaaz Publications. All rights reserved.

Email: ukaaz@yahoo.com; Website: www.ukaazpublications.com non-drug manipulations or regimens and even drugs are prescribed to maintain health and prevent disease (Yuan et al., 2016).

Every person is supposed to have a unique humoral constitution, which represents his/her healthy state. To maintain correct humoral balance, there is a power of self-preservation or adjustment called medicatrix naturae (tabiyat Mudabbira Badan) that works in living organisms. The medicatrix naturae works by decreasing disturbing inputs (removing obstacles to health and recovery) and adding positive inputs (a healthy environment). If, this power weakens, imbalance in the humoral composition is bound to occur and thereby causing disease. In Unani medicine, great reliance is placed on this power. The medicines used in this system, in fact, help the body regain this power to an optimum level and thereby restore humoral balance, thus retaining health. Also, correct diet and digestion are considered to maintain humoral balance (Jabin, 2011).

\section{Unani medicine in modern era}

The basic strengths of Unani System of Medicine are its holistic approach, temperament based prescription and treatment (Jabin, 2011). The use of natural drugs (mainly of plant origin), various therapeutic interventions, and regimens for prevention and treatment of diseases and health promotion is based on the concepts of holistic healing considering the individual's psychophysical wellbeing. Rational use of Unani medicines is usually free from adverse effects (Rahman et al., 2008). The toning up of the organs and the immune system is a unique approach of Unani medicine known for its beneficial effects. In chronic and some of the intractable diseases, these approaches have shown much utility in improving the quality of life of patients. For example, in musculoskeletal disorders, Unani System of Medicine uses various regimens (Ilaj bit Tadbeer) like cupping, massages and, exercises along with drug therapy for management of such disorders (Lone et al., 2012). In addition, Unani medicine also offers considerably effective management of many dissorders such as Vitiligo (Baras), Eczema (NärFärsé), Psoriasis (Da-al-Sadaf), Hepatitis (Iltihäb-i-Kabid), Filariasis (Dä-alFeel), Diabetes mellitus (Dhabetous Sukkare), Rheumatoid arthritis (Waja al-Mafasil), Sinusitis (Iltihäb-I-Tajäwéf-I Anf), Bronchial asthma (Zeeq-unNafas), etc. (Magner, 2005).

This medical system like any other growing science can not stay stagnant merely based on past belief. The modern form of Unani 
medicine that we see today is a result of a long period of evolution which occurred through exchange of knowledge between diverse countries, regions and communities. The system is constantly increasing its dimensions and scope by incorporating the contemporary scientific knowledge and the newest of technologies. Traditional concepts and understanding of the nature of disease are being correlated with modern biomedical concepts. The worldwide trend towards the utilization of traditional medicine in healthcare delivery systems has created an enormous need for scientific validation of their efficacy by incorporation of contemporary standards and techniques (WHO, 2010). There is growing awareness among the scientific community and the general public about the intrinsic value of our traditional systems of medicine, and as a result Ayurveda, Unani and Siddha have entered the mainstream to compliment conventional medicine. Therefore, we need to integrate the best of the different systems of medicine to meet the healthcare needs of contemporary society (Sen and Chakraborty, 2017). The Unani Materia Medica has attracted the attention of researchers in identifying active molecules and manufacturing commercial versions of traditional formulations (Sen and Chakraborty, 2015).

In order to scientifically validate and explore the hidden properties of various AYUSH systems of medicine, Govt. of India has established different research institutions, research councils and national institutes, Central Council for Research in Unani Medicine (CCRUM) is one such council which was established as a separate organization in 1978 with the objectives to initiate, develop and coordinate scientific research in fundamental and applied aspects of Unani medicine and to promote as well as assist institutions of research for the study of diseases, their prevention, causation, treatment, management and other remedial majors. This also facilitates the exchange of informations with other institutions following the similar objectives.

Since its establishment CCRUM, an autonomous organization under the Ministry of AYUSH, Government of India is actively engaged in research and development activities on the applied as well as fundamental aspects of Unani medicine. Over the past four decades of its existence, the Council has made significant strides in clinical research, drug standardization, survey and cultivation of medicinal plants, and literary research. Besides, research-oriented health extension services activities related to information, education and communication (IEC) have also been part of the Council's program. Presently, 23 centers of the Council and many other institutions are engaged in research on the Unani System of Medicine in different parts of the country. Under its clinical research program, the Council has established scientifically the therapeutic efficacy of various Unani drugs, which were in use for centuries (CCRUM, 2013).

CCRUM has published many monographs, research reports, success stories and scientific papers in reputed national and international journals. Over the years, one of the peripheral institute of CCRUMCentral Research Institute in Unani Medicine, Hyderabad has emerged as a specialty center of Unani treatment for skin diseases particularly Vitiligo and which has been upgraded to National Research Institute of Unani Medicine for Skin Disorders by Govt. of India in November, 2019.
Council has done noteworthy work in providing general medical care to the patients, bringing out innovative research outcomes, obtaining patents and bringing out scientific publications in various journals of international and national repute. To achieve excellence in research in the field of Unani medicine, the Council is collaborating with premium institutes like All India Institute of Medical Sciences (AIIMS) New Delhi, Council for Scientific and Industrial Research (CSIR), Jamia Millia Islamia, Jamia Hamdard, National Institute of Pharmaceutical Education and Research (NIPER) Hyderabad, National Institute of Cancer Prevention and Research (NICPR) Noida; Amity Institute, Noida and also with Aligarh Muslim University and various other premium institutes. The Council has also signed MoA with National Research Development Cooperation (NRDC), an institute of par excellence facilitating for patenting and commercialization of the technologies.

Recently, publication of special issue of Journal of AOAC International (Vol 103, No 3, 2020) by Oxford University press on analysis and regulations of traditional Unani medicine, which has covered many aspects of Unani medicine including basic principles, regulations, quality control and its modernization has also assisted considerably to bring the system to the attention of international audience (Ahmad, 2020).

The entire process of drug development, i.e., cultivation and collection of medicinal plants, standardization, preclinical toxicity and efficacy studies, and various phases of clinical trials are being undertaken with standard protocols and methodologies.

In order to prevent misappropriation of traditional knowledge and granting of wrong patents based on traditional knowledge, a Traditional Knowledge Digital Library (TKDL) has been set up to maintain inter alia a database of Unani formulations in patent compatible format. This database has been made available to International Patent Offices under non-disclosure agreement for the purpose of examining patent applications before the grant of patent.

It is the mandate of Ministry of AYUSH to endorse traditional systems of healing in accordance with their genius and acumen and help promotion of integrative medical facilities (Chandra and Patwardhan, 2018). For example, in recent pandemic situation, Ministry of AYUSH brought out a gazette notification based on the consultation of CDSCO, that allowed scientists, researchers, clinicians of any of recognized systems of medicine under IMCC Act, 1970, HCC Act 1973 and NMC Act 2019 (formerly IMC Act 1956) can undertake research on COVID-19 through Ayurveda, Siddha, Unani and Homeopathy systems including prophylactic measures, intervention during the quarantine, asymptomatic and symptomatic cases of COVID-19, public health research, survey and, lab based research, etc., to generate evidence.

\section{COVID-19 and Unani medicine}

It is true that the current pandemic has provided an opportunity to the AYUSH practitioners to contribute in sharing the strain on the existing healthcare system. Unani physicians can draw on the knowledge in the classical textbooks, contemporary scientific studies, and their experiences in similar clinical settings to deal with the pandemic. Common preventive approaches of Unani 
medicine for healthy life-style including healthy diet, clean air, adequate sleep and physical activity, and avoidance of disease causing factors are being advised.

Ministry of AYUSH has also brought out advisory for immunity boosting measures during the pandemic. As per Unani classical wisdom, improving immunity with immune boosters is one of the key approaches for prevention of disease and maintenance of health. Therefore, a strategy to enhance immunity and provide symptomatic relief in upper respiratory tract infection is advocated in these guidelines for qualified Unani practitioners (Nikhat and Fazil, 2020).

CCRUM has also launched population based interventional study on the impact of Unani prophylactic intervention for prevention of COVID-19 infection in high-risk population in six cities across India. The study is being conducted in COVID-19 high risk areas through the Council's centers in Lucknow, New Delhi, Mumbai, Aligarh, Srinagar and Bangalore. It is anticipated that the study will be able to generate evidence based data in the support of Unani Intervention for the prophylaxis against COVID-19 and pave new horizons in understanding the preventive potential of Unani Medicine.

There are many formulations of Unani medicine used since long for chronic disorders such as for liver, kidney, GIT and reproductive problems in which there are limited treatment options in modern medicine. However, these tradionally used formulations of Unani system provides unmatchable results without any known side effects. Other than many formulations used for immunomodulation, cold, cough, and fevers and general debility which have been used very commonly in this pandemic, there are many cardiprotective formulations doing well and showing unmatchable effects. Hence, Unani system provides a lots of traditional heritage, which can be used for development of new drugs for many life threatening diseases to empower AYUSH system and helps in nation building.

In the proper dissipations of emerging new scientific knowledge, scientific journals play key roles by publishing properly scrutinized and reviewed good quality research papers and review articles. In today's competitive world, the success of a journal depends on, to a large extent, getting good quality research findings including scientific concepts in the form of well-presented manuscripts as well as availing the services of efficient, experienced and unbiased reviewers. The journals should serve as a source of encouragement and inspiration to the scientists, young researchers in particular. Phytomedicine is truly multidisciplinary involving botany, chemistry, pharmacology, pharmacy, modern medicine, biochemistry, molecular biology, biophysics, and statistics. Keeping in view the ever increasing amount of awesome research work to be carried out in the development of phytomedicines and conventional medicines from plants, a matching increase in the number of good quality, reputed journals is a requirement. In this context, the emergence of 'Annals of Phytomedicine: An International Journal' is timely and with a commitment to excellence in publishing cutting edge research in all areas. It is a challenging job to run such a journal successfully. I am very happy to note that Annals of Phytomedicine: An International Journal is already, with certainty, on its way towards accomplishing its mission and reaching to its zenith.

\section{Conflict of interest}

The author declares that there are no conflicts of interest relevant to this article.

\section{References}

Ahmad, S. (2020). Analysis and Tegulation of Traditional Indian Unani Medicines. J. AOAC Int., 103(3):607-608. doi: 10.5740/ jaoacint.19-0320

CCRUM (2013). Unani system of medicine: The science of health and healing.

Chandra, S. and Patwardhan, K. (2018). Allopathic, AYUSH and informal medical practitioners in rural India: A prescription for change. J. Ayurveda Integr. Med., 9(2):143-150.

Jabin, F. (2011). A guiding tool in Unani Tibb for maintenance and preservation of health: A review study. African J. Tradit. Complement. Altern. Med., 8(5 Suppl):140-143.

Kleisiaris, C.F.; Sfakianakis, C. and Papathanasiou, I.V. (2014). Healthcare practices in ancient Greece: The hippocratic ideal. J. Med. Ethics Hist. Med., 7(6).

Lone, A.H.; Ahmad, T.; Anwar, M.; Sofi, G.; Imam, H. and Habib, S. (2012). Perception of health promotion in Unani herbal medicine. J. Herb. Med., 2(1):1-5.

Magner, L.N. (2005). A history of medicine.

Nikhat, S. and Fazil, M. (2020). Overview of COVID-19; its prevention and management in the light of Unani medicine. Sci. Total Environ., 728: 138859

Rahman, S.; Khan, R. and Latif, A. (2008). Importance of pharmacovigilance in Unani system of medicine. Indian J. Pharmacol., 40(1):17-20.

Ravishankar, B. and Shukla, V.J. (2007). Indian systems of medicine: A brief profile. African J. Tradit. Complement. Altern. Med., 4(3):319-337.

Sen, S. and Chakraborty, R. (2015). Toward the integration and advancement of herbal medicine: A focus on traditional Indian medicine. Bot. Targets Ther., 33(5):33-44.

Sen, S. and Chakraborty, R. (2017). Revival, modernization and integration of Indian traditional herbal medicine in clinical practice: Importance, challenges and future. J. Tradit. Complement. Med., 7(2):234-244

Sudhir, H. (2014). Role of Unani System of Medicine in management of orofacial diseases: A review. J. Clin. Diagnostic Res., 8(10):12-15.

WHO (2010). Benchmarks for training in Unani medicine.

Yuan, H.; Ma, Q.; Ye, L. and Piao, G. (2016). The traditional medicine and modern medicine from natural products. Molecules, 21(5):559 http://dx.doi.org/10.21276/ap.2020.9.2.1 


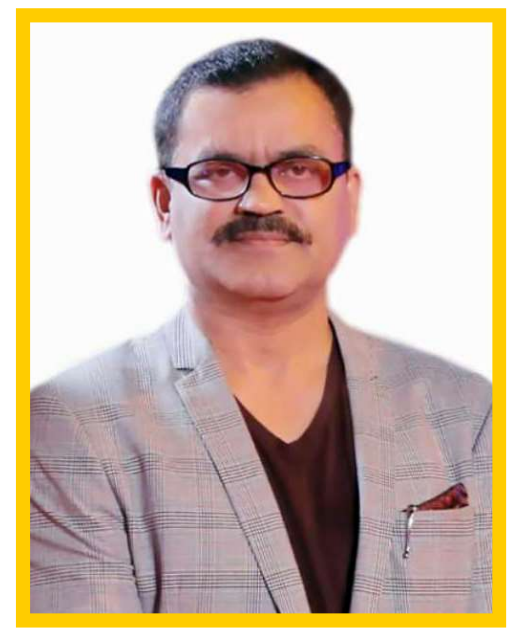

Professor Asim Ali Khan

Director General, Central Council for Research in Unani Medicine (CCRUM), Ministry of AYUSH, Govt. of India, New Delhi-110058, India

\section{Biography}

Professor Asim Ali Khan is the Director General of Central Council for Research in Unani Medicine, Ministry of AYUSH, Government of India. He is directing and coordinating the Preclinical, Clinical, safety and toxicity studies of unani drugs, Public Health intervention Literary research activities, publication division, Intramural research programs, Extra mural research programs, collaborative research programs with leading academic as well scientific institutions of the national and international importance, expansion/development of infrastructure-buildings, new campuses of Regional Research Institute of Unani Medicine/National Research Institutes of Unani Medicine/research facilities/Medical Centers, organizing national/ International Seminars and conferences, social media activities as well as publication of Scientific Journals through its 23 institutes spread across India.

$\mathrm{He}$ is also the Member of Board of Governors, Central Council of Indian Medicine, Govt. of India. He is involved and responsible for Policy making, Planning, implementation and Governance of Quality Education, Training and Researches in Ayurveda, Unani and Sidhha Sciences in AYUSH systems.

He is a member on various important committees of Govt. of India;

- Member, NITI AYOG Working Group Committee on Integration of Research, Govt. of India

- Member, Interdisciplinary AYUSH R\&D Task Force, Govt. of India

- Member, CSIR, Ministry of Science and Technology, Govt. of India-Ministry of AYUSH Working Group for Cooperation of activities of common interest

- Member, Advisory Committee of CSIR, Ministry of Science and Technology-Traditional Knowledge Digital Library (CSIRTKDL) Unit
- Expert member, WHO Committee/s for developing the Standard Terminologies of Unani Medicine and Committee for developing Benchmark for education and Practice of Unani Medicine.

- Member, Scientific Committee of Pharmacopoeia Commission of Indian Medicine and Homoeopathy (PCIM \& H), Govt. of India

- Member Secretary, Governing body of CCRUM, Ministry of AYUSH, Govt. of India

- Member Secretary, Executive Committee of CCRUM, Ministry of AYUSH, Govt. of India

- Member Secretary, Standing Finance Committee of CCRUM, Ministry of AYUSH, Govt. of India

- Member Secretary, Scientific Advisory Committee of CCRUM, Ministry of AYUSH, Govt. of India

- Member Secretary, Unani Pharmacopoea Committee, CCRUM, Ministry of AYUSH, Govt. of India

- Member, Scientific Advisory Committee, National Institute of Unani Medicine, (NIUM), Govt. of India, Bangalore

- Member, Academic Council, Baba Ghulam Shah Badshah University, Rajouri, J\&K.

- Member, Managing Committee AKTC, Aligarh Muslim University, Aligarh, UP, India

- Member, Technical Committee AYUSH, GRID, Ministry of AYUSH, Govt. of India

- Member, Expert group on Quality control and standardization of ASU\&H drugs, constituted by Quality Council of India. Oct. 2018

- Member, Faculty Committee, School of Unani Medical Education and Research, Jamia Hamdard (University), New Delhi 
Besides, being a member on Research Project Approval committees of Ministry of AYUSH, presently and in the past, he has been the Member of Board of Governors and Internal Quality Assurance Cell (IQAC ) of Jamia Hamdard (University), New Delhi

$\mathrm{He}$ is also the Editor In Chief; Hippocratic Journal of Unani Medicine, Jahane Tib Journal of Unani Medicine and News Letter, CCRUM, Ministry of AYUSH, Govt. of India

With his committed efforts and vision, he has been able to spread the knowledge of Unani System of Medicine to many countries like Nigeria, Congo, Malaysia, Syria, Iran, China and Bahrain. Students from these countries have been formally enrolled in regular Unani Medicine education programs of study at Jamia Hamdard.

He has a vast experience in Clinical Medicine, Research and Teaching. His area of interest is Cardio vascular and Thoracic disorders and has expertise in fast emerging 'Life Style Disorders' like hypertension.
He has guided and supervised about 20 research studies of many Post Graduate Unani Scholars and has mentored the PhD Scholar/s.

He has around 100 publications including research papers, Books, Chapter in Book and Articles and has organized, attended/Chaired/ presented/delivered Keynote addresses at many national \& International Conferences, Seminars and Symposia. He has also been part of Govt. of India delegation to Iran.

Recently, he was nominated by Govt. of India and delivered a Talk on Integration of Health Care at 'Geneva Health Forum' where India was a Country Guest of Honor.

He has signed many MoUs with leading scientific and research organisations at national and International levels.

His articles on health related matters frequently appear in various health magazines as well as National Newspapers. His Interviews and Talks on health related concerns have been telecasted from various 'National News TV Channels' like E TV and Zee TV, etc. 